\title{
Realistic Vehicular Mobility Impact of FTM, IDM, IDM-IM and IDM-LC on VANETs
}

\author{
Md. Habibur Rahman \\ Dept. of Computer Science \\ AIUB, Bangladesh
}

\author{
Md. Monzur Morshed \\ TigerHATS \\ Dhaka, Bangladesh
}

\author{
Meftah Ur Rahman \\ Dept. of Computer Science \\ George Mason University, USA
}

\begin{abstract}
VANETs are composed of a number of vehicles moving on city roads, able to interconnect with one another without a fixed infrastructure. Improvisation of a new vehicular communication system should entitle a node to travel safely with high speed mobility while maintaining seamless interconnectivity. To evaluate the impact of mobility models such as FTM, IDM, IDM-IM and IDM-LC on VANETs routing protocol, VanetMobiSim is introduced to design a realistic vehicular mobility model for an urban scenario of Dhaka city. The experimental results suggest several issues e.g. lower packet drop rate, delay, jitter and route cost, etc are required to be considered before preparing a realistic application of VANET. The simulation results have been measured by different performance metrics such as drop, delay, jitter, round-trip time, throughput, route cost and mean hop etc.
\end{abstract}

\section{Keywords}

VANET; AODV; AOMDV; DYMO; OLSR; FTM; IDM-IM; IDM-LC; IDM; IEEE 802.11p;

\section{INTRODUCTION}

Vehicular Ad-Hoc Network (VANET) is an extension of Mobile Ad-Hoc Network (MANET). It characterizes a rapidly progressive research area. It is regarded as an extreme case of mobile ad hoc network. In vehicular ad hoc networks (VANETs), vehicles communicate with roadside units (RSUs), referred to as vehicle-to-infrastructure (V2I) communications. In addition, vehicles can communicate with each other in an infrastructure less mode, referred to as vehicle-to-vehicle (V2V) communications [1]. It is a vehicular communication system for traffic safety, transport efficiency and data service. It enables public safety applications that can preserve lives and advance traffic flow [2]. Compared to MANETs, VANETs simulation provides some unique features such as highly dynamic topology, frequently disconnected network, patterned mobility, propagation model, on-board sensors, unlimited battery power and storage in a vehicular environment [3]. VANETs routing protocols can be categorized into topology-based and geographic (Positionbased) routing protocol. Topology-based routing protocols are used for links' information that exists in the network to do packet forwarding. It can be divided into proactive and reactive routing protocol. The performance of the VANET routing protocol can vary by additional reasons such as communication mode, vehicle/node density fluctuations, and vehicle/node mobility [4]. The node mobility can be expressed as node position, velocity, acceleration and deceleration in existence of neighboring nodes, line up at road intersections, traffic jam made by cross roads, traffic lights, node density and traffic congestion [5]. It is tough to look at those factors, particularly in an extreme mobility case. The
IEEE $802.11 \mathrm{p}$ offers various stages of service importance based on different type of traffic pattern [1]. VanetMobiSim can provide the facility to design a real world mobility scenario of a particular area. It can be applied to dissect the traffic of a metropolis or a particular country. In this study, VanetMobiSim has been used to design a realistic vehicular mobility pattern for vehicular communications. For experimental evaluations, it is compared according to the impact of Fluid Traffic Model (FTM), Intelligent Driver Model (IDM), Intelligent Driver Model with Intersection Management (IDM-IM) and Intelligent Driver Model with Lane Changes (IDM-LC) etc. While doing this experiment, AODV, AOMDV, DYMO and OLSR routing protocols with respect to dissimilar parameter of QoS metrics have been used.

\section{RELATED WORK}

Numerous surveys have been conducted to assess the performance of VANETs using several routing protocols along with different mobility models. In [4], the author has assessed the performance of Vehicular Ad-Hoc Networks using clustering of three different regions (urban, suburban and industrial) and traffic lights into the IDM-IM by AOMDV and AODV routing protocols with two dissimilar cases of traffic pattern. But the author has used existing IEEE $802.11 \mathrm{~b}$ protocol instead of IEEE $802.11 \mathrm{p}$ MAC protocols. It is known that Wireless Access in Vehicular Environments (WAVE) or IEEE $802.11 \mathrm{p}$ provides enhancements to the physical and MAC layers. Likewise, several researchers use Two Ray Ground propagation model with IEEE 802.11b MAC protocol for comparing VANETs performance using different routing protocol, traffic pattern and various mobility models [5-9]. W. Alasmary et al. [1] presented the impact of mobility in IEEE $802.11 \mathrm{p}$ infrastructureless vehicular networks by investigating certain mobility factors. In their work, they indicated that relative speed has an important impact on channel access at the MAC layer, brushing off the number of communicating nodes. In [10], the authors have offered that $802.11 \mathrm{p}$ gives effective service differentiation mechanism that can be appropriate for the mission-critical ITS application. They evaluated the MAC layer performance without putting on any realistic vehicular mobility model for VANETs. V. Cabrera et al. [11] suggested some guidelines which could improve the performance of VANET routing such as store-carry-forward paradigm, beacons dependency, add useful information and careful selection of forwarding criteria. In their study, they have evaluated simulation-based study subject to vehicular mobility patterns. \section{REVIEW OF ROUTING PROTOCOLS} Ad-Hoc On-demand Distance Vector (AODV) routing protocol maintains routing tables with single entry at each destination. When a source node stops sending data packet, 
the links will timeout and finally be removed from intermediate node routing tables [12-13]. Ad-Hoc On-demand Multipath Distance Vector (AOMDV) calculates link-disjoint paths and multiple loop-free paths but nodes are uninformed of comparative movement and positioning. The Link-disjoint feature of AOMDV ensures that no two parallel paths between a source-destination pair will receive a mutual connection [14-16]. Dynamic MANET On-demand (DYMO) routing protocol facilitates reactive, multi-hop unicast routing between participating DYMO routers. Routes are discovered on demand once a source node requires creating a route to the destination. Here, the Route Request messages flood the network using broadcast [17]. To optimize the performance of Optimized Link State Routing (OLSR) protocol, Multipoint Relay (MPR) nodes are applied to the number of packets broadcasted on the network during the flooding process. It provides optimal routes in terms of number of hops [18]

\section{MOBILITY MODEL}

VanetMobiSim provides a realistic vehicular movement pattern. It includes vehicle to infrastructure (V2I) and vehicle to vehicle $(\mathrm{V} 2 \mathrm{~V})$ association. It combines the traffic lights, stop signs and activity based macro-mobility. FTM defines traffic congestion scenarios, but still cannot reconstruct queuing situations, nor can it properly manage the behavior of cars in the presence of road intersections [19]. IDM describes driver's behavior relating to their instantly earlier vehicle. This model defines car mobility on single lanes, but do not think through the case in which multiple vehicular flows have to interconnect, as to the existence of intersections [19]. IDMIM is capable of smart intersection management as well as slow down and stop at crossroads, or act according to traffic lights, if present. In both situations, it only behaves on the first vehicle on each road, as IDM automatically adjusts the behavior of cars behind the leading car [19]. IDM-LC mobility model provides opportunities for vehicles to alternate lanes and overtaking among other vehicles in the presence of multi-lane roads. These two features occur with parting of traffic flows on different lanes of the similar roads and the overtaking model itself [19].

\subsection{System Model}

The system model demonstrated a realistic vehicular mobility model in a particular area of Dhaka city using FTM, IDM-IM, IDM-LC and IDM mobility model to see the traffic status of the area as shown Figure 1. In four mobility models, the number of interaction with a traffic light is 500 . The length of Traffic light is 10 second. Two lanes have been used in the study. The maximum number of multi-lane roads is 10 . The Six seconds is the maximum stay duration at destination. The two second is the minimum stay duration at destination. In IDM-IM and IDM-LC, the maximal acceleration of vehicle movement is $0.6 \mathrm{~m} / \mathrm{s}^{2}$. The "comfortable" deceleration of vehicle movement is $0.9 \mathrm{~m} / \mathrm{s}^{2}$. " $1 \mathrm{~m}$ " distance to a standing node (jam distance) is kept at a minimum. The safe time headway for a node is " $0.5 \mathrm{sec}$ ". The step for recalculating movement parameter is 1 (one) second. The intersections at the borders of the map are ignored. The vehicle length is 5 meters. The visibility distance is 200 meters. In IDM-LC, the politeness factor of drivers when changing lane is 0.5 meters. The threshold acceleration for lane change is $0.5 \mathrm{~m} / \mathrm{s}^{2}$. The maximum "safe" deceleration is $2 \mathrm{~m} / \mathrm{s}^{2}$. In FTM, the jam distance is " 1 meter".

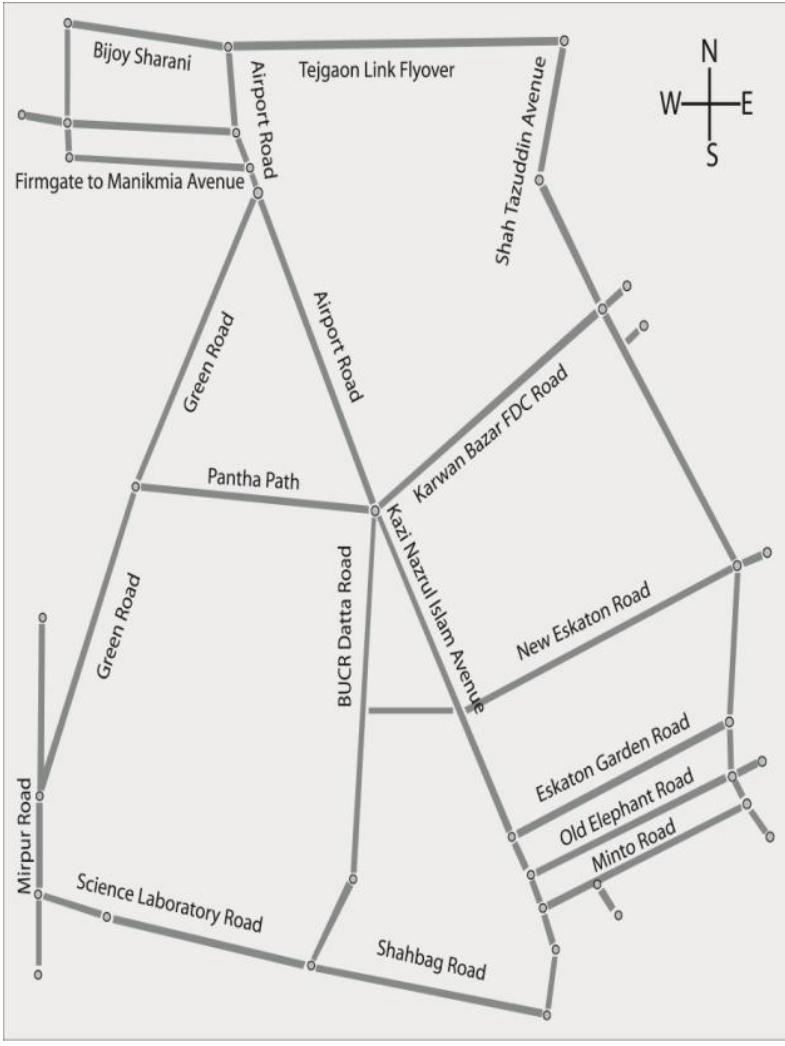

Figure 1: Demonstration of mobility model for simulation

\section{SIMULATION PARAMETERS}

All nodes use $802.11 \mathrm{p}$ MAC operation at $6 \mathrm{Mbps}$. The transmission range is 250 meters. For vehicular safety communication, it has broadcasted message between vehicles. For experimental purposes, the simulation area is $1000 \mathrm{X}$ $1000 \mathrm{~m}^{2}$. The real world simulation area is more eminent than the simulation area used this study. Figure 2 demonstrated the simulation topology in NS2 environment.

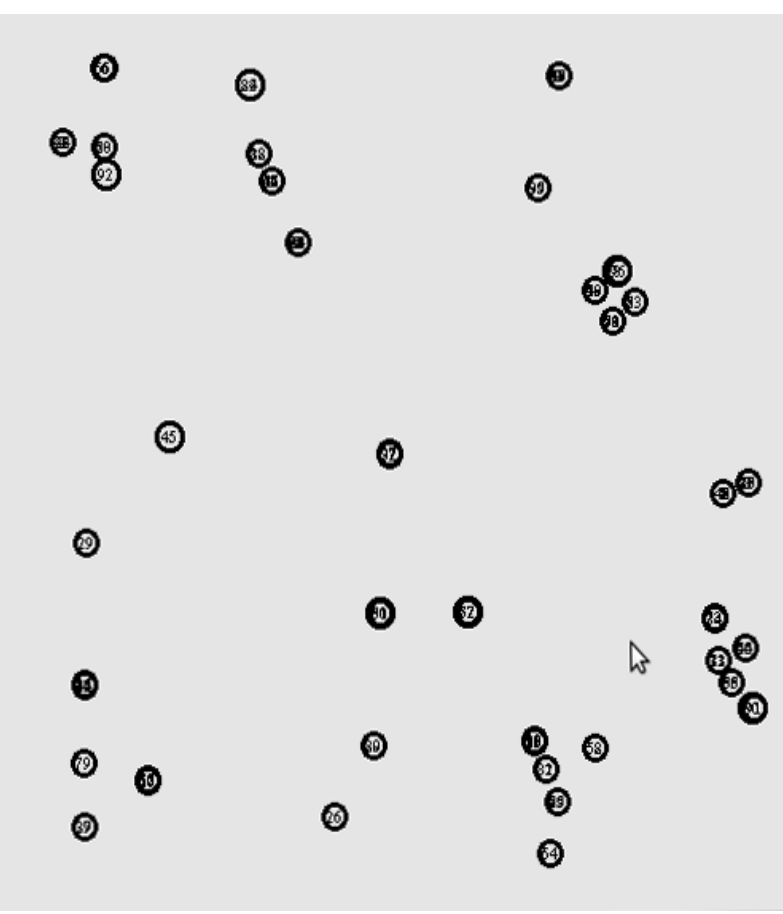

Figure 2: Simulation Topology in NS2 environment 
Table 1. Simulation Parameters

\begin{tabular}{|c|c|}
\hline Parameter & Value \\
\hline MAC Type & IEEE 80211p \\
\hline Channel Type & Wireless \\
\hline Mobility Model & As explained in section 4.1 \\
\hline Simulation Area & 1000 X $1000 \mathrm{~m}^{2}$ \\
\hline Simulation Time & $100 \mathrm{sec}$ \\
\hline Traffic Model & 46 TCP Vegas connection \\
\hline Packet Size & 1000 bytes \\
\hline No. of Vehicles & 100 \\
\hline Vehicle Speed & $10-80$ Km/hr \\
\hline Packet Rate & 4 packets / sec \\
\hline Radio Propagation & Nakagami \\
\hline Routing Protocols & AODV, AOMDV, DYMO, OLSR \\
\hline
\end{tabular}

\section{QUALITY EVALUATION}

For Quality evaluation, it is presented QoS (Quality of Service) metrics with other performance metrics.

\subsection{QoS Metrics}

\subsubsection{Drop}

The packet drop is counted by the total number of packets dropped when a source node transmits data packet through the network for the destination node. The lower drop rate indicates better performance in VANETs. Packet drop $\left(\mathrm{P}_{\mathrm{d}}\right)$ can be estimated using Eq. 1.

$$
\mathrm{P}_{\mathrm{d}}=\sum \mathrm{P}_{\mathrm{r}}-\sum P_{\mathrm{s}}
$$

Where, $\mathrm{P}_{\mathrm{r}}$ and $\mathrm{P}_{\mathrm{s}}$ are the number of packets received and sent.

\subsubsection{Throughput}

Throughput means the total number of packets that have been successfully delivered to the destination nodes. Normally, throughputs are measured in kbps, Mbps and Gbps. The higher throughput result shows better performance. Throughput $\left(\mathrm{T}_{\mathrm{h}}\right)$ can be defined as Eq. 2.

$$
T_{h}=\sum N_{t}
$$

Where, $\mathrm{N}_{\mathrm{t}}$ is the number of data packet bytes in a particular time.

\subsubsection{Delay}

A particular packet is transmitted from source to destination and calculates the difference between sending times and received times. The data were collected only successfully delivered packets. The packet delay always expected lower in VANETs. Delay $\left(D_{\mathrm{i}}\right)$ can be defined as Eq. 3 .

$$
\mathrm{D}_{\mathrm{i}}=\mathrm{R}_{\mathrm{t}}-\mathrm{S}_{\mathrm{t}}
$$

Where, $R_{t}$ and $S_{t}$ are the time of packet received and transmitted.

\subsubsection{Jitter}

Jitter is the variance of the packet arrival time. The delays between the different packets need to be low for best performance in VANETs. Jitter $\left(\mathrm{J}_{\mathrm{i}}\right)$ can be defined by Eq. 4 .

$$
\mathrm{J}_{\mathrm{i}}=\mathrm{D}_{\mathrm{i}+1}-\mathrm{D}_{\mathrm{i}} \quad \text { where, } \mathrm{i}=1,2 \ldots \mathrm{n}
$$

\subsubsection{Round-trip Time (RTT)}

RTT is the time needed for a TCP packet to transmit from a particular source node to a particular destination node and come back with acknowledgment to source node from destination node. RTT of the TCP packets is needed to be low for best performance in VANETs. RTT $\left(\mathrm{R}_{\mathrm{i}}\right)$ can be defined by Eq. 5.

$$
\mathrm{R}_{\mathrm{i}}=\mathrm{A}_{\mathrm{i}}-\mathrm{S}_{\mathrm{i}} \quad \text { where, } \mathrm{i}=1,2,3 \ldots \mathrm{n}
$$

Where, $A_{i}$ and $S_{i}$ are the time of TCP packet sent and acknowledgement received.

\subsection{Other Performance Metrics}

\subsubsection{Average Throughput}

The amount of data transmitted by the network divided by time period. It is the sum of data rates that are delivered to all vehicles in VANETs. Average throughput $\left(A_{h}\right)$ can be calculated using Eq. 6.

$$
A_{h}=\left(\frac{\sum \mathrm{N}_{\mathrm{t}}}{\mathrm{T}_{\mathrm{n}}}\right) *\left(\frac{8}{1000}\right)
$$

Where, $T_{n}$ is the total number of vehicles.

\subsubsection{Normalized Routing Load (NRL)}

The total number of routing packets transmitted per data packet sent at the destination. Each hop-wise transmission of a routing is counted as one transmission. It is the sum of all control packets sent by all vehicles in the area to discover and maintain the route. Normalized Routing Load $\left(\mathrm{N}_{1}\right)$ is calculated by Eq. 7 .

$$
N_{l}=\frac{\sum R_{p}}{\sum P_{r}}
$$

Where, $\mathrm{R}_{\mathrm{p}}$ is the number of routing packets in layer 2 (MAC).

\subsubsection{Mean Hop}

The total number of control or routing packets forwarded by routing protocol during the simulation to send data packet delivered to the destination. All packets sent or forwarded at the network layer is required at least one hop to the destination. Mean Hop $\left(\mathrm{M}_{\mathrm{h}}\right)$ can be defined as Eq. 8 .

$$
\mathrm{M}_{\mathrm{h}}=\frac{\sum \mathrm{P}_{\mathrm{f}}}{\sum \mathrm{P}_{\mathrm{s}}}+1
$$

Where, $\mathrm{P}_{\mathrm{f}}$ and $\mathrm{P}_{\mathrm{s}}$ are the number routing packet forwarded and sent respectively.

\subsubsection{Packet Delivery Ratio (PDR)}

The ratio of the data packets sent to the destination to those generated by the traffic sources. PDR is calculated by Eq. 9 .

$$
P D R=\frac{\sum P_{r}}{\sum P_{s}}
$$

\subsubsection{Routing Cost}

It is the ratio of routing bytes to traffic packet bytes. Routing Cost $\left(R_{c}\right)$ can be calculated using Eq. 10 .

$$
\mathrm{R}_{\mathrm{c}}=\frac{\mathrm{N}_{\mathrm{r}}}{\mathrm{N}_{\mathrm{t}}}
$$


Where, $\mathrm{N}_{\mathrm{r}}$ is the number route bytes and $\mathrm{N}_{\mathrm{t}}$ is the number of traffic packet bytes.

\section{RESULT ANALYSIS}

The simulation result is achieved by using the four topologybased routing protocols in VANETs. The experiment is implemented using VanetMobiSim and NS2 (NS 2.34 and NS 2.35) in an Intel (R) Core (TM) i7-2670QM $2.20 \mathrm{GHz}$ machine running on 4GB RAM, Windows 7 and Ubuntu 10.04 platform. To evaluate the impact of four mobility models in VANETs we considered the protocols with respect to QoS metrics and other performance evaluation metrics.

\subsection{Quantitative Verification}

The quantitative comparison measures the performance of AODV, AOMDV, DYMO, and OLSR routing protocol using FTM, IDM, IDM-IM and IDM-LC realistic mobility model in Vehicular Ad-Hoc Networks along with dissimilar parameter of QoS metrics such as delay, jitter, round-trip time, packet drop and throughput for understanding the behavior of TCP Vegas traffic packet in the dynamic network simulation scenario. It also compares mobility impact of those routing protocol performances with several other performance evaluation metrics such as Packet Delivery Ratio (PDR), Route Cost, Mean hop, Average Throughput and Normalized Routing Load (NRL). The presented simulation results in the following Table 2-17 and Figure -13.

Table 2. Number of packet drop for AODV

\begin{tabular}{|c|c|c|c|c|}
\hline \multirow{2}{*}{$\begin{array}{c}\text { Packet } \\
\text { Type }\end{array}$} & $\begin{array}{c}\text { Mobility } \\
\text { Model }\end{array}$ & $\begin{array}{c}\text { Total } \\
\text { Sent } \\
\text { packets }\end{array}$ & $\begin{array}{c}\text { Total } \\
\text { Received } \\
\text { packets }\end{array}$ & $\begin{array}{c}\text { Total } \\
\text { Dropped } \\
\text { packets }\end{array}$ \\
\hline \multirow{2}{*}{$\begin{array}{c}\text { TCP } \\
\text { Vegas }\end{array}$} & FTM & 51384 & 50453 & 931 \\
\cline { 2 - 5 } & IDM-IM & 64698 & 63729 & 969 \\
\cline { 2 - 5 } & IDM-LC & 59733 & 58818 & 915 \\
\cline { 2 - 5 } & IDM & 61044 & 60072 & 972 \\
\hline
\end{tabular}

Table 3. Number of packet drop for AOMDV

\begin{tabular}{|c|c|c|c|c|}
\hline \multirow{2}{*}{$\begin{array}{c}\text { Packet } \\
\text { Type }\end{array}$} & $\begin{array}{c}\text { Mobility } \\
\text { Model }\end{array}$ & $\begin{array}{c}\text { Total } \\
\text { Sent } \\
\text { packets }\end{array}$ & $\begin{array}{c}\text { Total } \\
\text { Received } \\
\text { packets }\end{array}$ & $\begin{array}{c}\text { Total } \\
\text { Dropped } \\
\text { packets }\end{array}$ \\
\hline \multirow{3}{*}{$\begin{array}{c}\text { TCP } \\
\text { Vegas }\end{array}$} & FTM & 41862 & 40861 & 1001 \\
\cline { 2 - 5 } & IDM-IM & 71221 & 70559 & 662 \\
\cline { 2 - 5 } & IDM-LC & 65363 & 64638 & 725 \\
\cline { 2 - 5 } & IDM & 64695 & 63981 & 714 \\
\hline
\end{tabular}

Table 4. Number of packet drop for DYMO

\begin{tabular}{|c|c|c|c|c|}
\hline \multirow{2}{*}{$\begin{array}{c}\text { Packet } \\
\text { Type }\end{array}$} & $\begin{array}{c}\text { Mobility } \\
\text { Model }\end{array}$ & $\begin{array}{c}\text { Total } \\
\text { Sent } \\
\text { packets }\end{array}$ & $\begin{array}{c}\text { Total } \\
\text { Received } \\
\text { packets }\end{array}$ & $\begin{array}{c}\text { Total } \\
\text { Dropped } \\
\text { packets }\end{array}$ \\
\hline \multirow{2}{*}{$\begin{array}{c}\text { TCP } \\
\text { Vegas }\end{array}$} & FTM & 21817 & 21055 & 762 \\
\cline { 2 - 5 } & IDM-IM & 58174 & 57396 & 778 \\
\cline { 2 - 5 } & IDM-LC & 55183 & 54446 & 737 \\
\cline { 2 - 5 } & IDM & 54842 & 54154 & 688 \\
\hline
\end{tabular}

Table 5. Number of packet drop for OLSR

\begin{tabular}{|c|c|c|c|c|}
\hline \multirow{2}{*}{$\begin{array}{c}\text { Packet } \\
\text { Type }\end{array}$} & $\begin{array}{c}\text { Mobility } \\
\text { Model }\end{array}$ & $\begin{array}{c}\text { Total } \\
\text { Sent } \\
\text { packets }\end{array}$ & $\begin{array}{c}\text { Total } \\
\text { Received } \\
\text { packets }\end{array}$ & $\begin{array}{c}\text { Total } \\
\text { Dropped } \\
\text { packets }\end{array}$ \\
\hline \multirow{3}{*}{$\begin{array}{c}\text { TCP } \\
\text { Vegas }\end{array}$} & FTM & 31881 & 31118 & 763 \\
\cline { 2 - 5 } & IDM-IM & 47443 & 46654 & 789 \\
\cline { 2 - 5 } & IDM-LC & 53353 & 52646 & 707 \\
\cline { 2 - 5 } & IDM & 62191 & 61494 & 697 \\
\hline
\end{tabular}

Table 6. Throughput for AODV

\begin{tabular}{|c|c|c|c|}
\hline $\begin{array}{c}\text { Packet } \\
\text { Type }\end{array}$ & $\begin{array}{c}\text { Mobility } \\
\text { Model }\end{array}$ & $\begin{array}{c}\text { Total Sending } \\
\text { Throughput } \\
\text { (kbps) }\end{array}$ & $\begin{array}{c}\text { Total Receiving } \\
\text { Throughput } \\
\text { (kbps) }\end{array}$ \\
\hline \multirow{2}{*}{$\begin{array}{c}\text { TCP } \\
\text { Vegas }\end{array}$} & FTM & 51384000 & 50453000 \\
\cline { 2 - 4 } & IDM-IM & 64698000 & 63729000 \\
\cline { 2 - 4 } & IDM-LC & 59733000 & 58818000 \\
\cline { 2 - 4 } & IDM & 61044000 & 60072000 \\
\hline
\end{tabular}

Table 7. Throughput for AOMDV

\begin{tabular}{|c|c|c|c|}
\hline $\begin{array}{c}\text { Packet } \\
\text { Type }\end{array}$ & $\begin{array}{c}\text { Mobility } \\
\text { Model }\end{array}$ & $\begin{array}{c}\text { Total Sending } \\
\text { Throughput } \\
\text { (kbps) }\end{array}$ & $\begin{array}{c}\text { Total Receiving } \\
\text { Throughput } \\
\text { (kbps) }\end{array}$ \\
\hline \multirow{2}{*}{$\begin{array}{c}\text { TCP } \\
\text { Vegas }\end{array}$} & FTM & 41862000 & 40861000 \\
\cline { 2 - 4 } & IDM-IM & 71221000 & 70559000 \\
\cline { 2 - 4 } & IDM-LC & 65363000 & 64638000 \\
\cline { 2 - 4 } & IDM & 64695000 & 63981000 \\
\hline
\end{tabular}

Table 8. Throughput for DYMO

\begin{tabular}{|c|c|c|c|}
\hline $\begin{array}{c}\text { Packet } \\
\text { Type }\end{array}$ & $\begin{array}{c}\text { Mobility } \\
\text { Model }\end{array}$ & $\begin{array}{c}\text { Total Sending } \\
\text { Throughput } \\
\text { (kbps) }\end{array}$ & $\begin{array}{c}\text { Total Receiving } \\
\text { Throughput } \\
\text { (kbps) }\end{array}$ \\
\hline \multirow{4}{*}{$\begin{array}{c}\text { TCP } \\
\text { Vegas }\end{array}$} & FTM & 21817000 & 21055000 \\
\cline { 2 - 4 } & IDM-IM & 58174000 & 57396000 \\
\cline { 2 - 4 } & IDM-LC & 55183000 & 54446000 \\
\cline { 2 - 4 } & IDM & 54842000 & 54154000 \\
\hline
\end{tabular}

Table 9. Throughput for OLSR

\begin{tabular}{|c|c|c|c|}
\hline $\begin{array}{c}\text { Packet } \\
\text { Type }\end{array}$ & $\begin{array}{c}\text { Mobility } \\
\text { Model }\end{array}$ & $\begin{array}{c}\text { Total Sending } \\
\text { Throughput } \\
\text { (kbps) }\end{array}$ & $\begin{array}{c}\text { Total Receiving } \\
\text { Throughput } \\
\text { (kbps) }\end{array}$ \\
\hline \multirow{3}{*}{$\begin{array}{c}\text { TCP } \\
\text { Vegas }\end{array}$} & FTM & 31881000 & 31118000 \\
\cline { 2 - 4 } & IDM-IM & 47443000 & 46654000 \\
\cline { 2 - 4 } & IDM-LC & 53353000 & 52646000 \\
\cline { 2 - 4 } & IDM & 62191000 & 61494000 \\
\hline
\end{tabular}


Table 10. PDR, Drop and Avg. Throughput for AODV

\begin{tabular}{|c|c|c|c|c|}
\hline $\begin{array}{c}\text { Packet } \\
\text { Type }\end{array}$ & $\begin{array}{c}\text { Mobility } \\
\text { Model }\end{array}$ & $\begin{array}{c}\text { PDR } \\
(\%)\end{array}$ & $\begin{array}{c}\text { Drop } \\
(\%)\end{array}$ & $\begin{array}{c}\text { Average } \\
\text { Throughput } \\
\text { (kbps) }\end{array}$ \\
\hline \multirow{3}{*}{$\begin{array}{c}\text { TCP } \\
\text { Vegas }\end{array}$} & FTM & 98.19 & 1.81 & 4094.47 \\
\cline { 2 - 5 } & IDM-IM & 98.50 & 1.50 & 5171.80 \\
\cline { 2 - 5 } & IDM-LC & 98.47 & 1.53 & 4773.26 \\
\cline { 2 - 5 } & IDM & 98.41 & 1.59 & 4875.08 \\
\hline
\end{tabular}

Table 11. PDR, Drop and Avg. Throughput for AOMDV

\begin{tabular}{|c|c|c|c|c|}
\hline $\begin{array}{c}\text { Packet } \\
\text { Type }\end{array}$ & $\begin{array}{c}\text { Mobility } \\
\text { Model }\end{array}$ & $\begin{array}{c}\text { PDR } \\
(\%)\end{array}$ & $\begin{array}{c}\text { Drop } \\
(\%)\end{array}$ & $\begin{array}{c}\text { Average } \\
\text { Throughput } \\
(\mathbf{k b p s})\end{array}$ \\
\hline \multirow{3}{*}{$\begin{array}{c}\text { TCP } \\
\text { Vegas }\end{array}$} & FTM & 97.61 & 2.39 & 3315.98 \\
\cline { 2 - 5 } & IDM-IM & 99.07 & 0.93 & 5726.06 \\
\cline { 2 - 5 } & IDM-LC & 98.89 & 1.11 & 5245.56 \\
\cline { 2 - 5 } & IDM & 98.90 & 1.10 & 5192.32 \\
\hline
\end{tabular}

Table 12. PDR, Drop and Avg. Throughput for DYMO

\begin{tabular}{|c|c|c|c|c|}
\hline \multirow{2}{*}{$\begin{array}{c}\text { Packet } \\
\text { Type }\end{array}$} & $\begin{array}{c}\text { Mobility } \\
\text { Model }\end{array}$ & $\begin{array}{c}\text { PDR } \\
(\%)\end{array}$ & $\begin{array}{c}\text { Drop } \\
(\%)\end{array}$ & $\begin{array}{c}\text { Average } \\
\text { Throughput } \\
\text { (kbps) }\end{array}$ \\
\hline \multirow{2}{*}{$\begin{array}{c}\text { TCP } \\
\text { Vegas }\end{array}$} & FTM & 96.51 & 3.49 & 1708.70 \\
\cline { 2 - 5 } & IDM-IM & 98.66 & 1.34 & 4357.85 \\
\cline { 2 - 5 } & IDM-LC & 98.66 & 1.34 & 4418.45 \\
\cline { 2 - 5 } & IDM & 98.75 & 1.25 & 4418.45 \\
\hline
\end{tabular}

Table 13. PDR, Drop and Avg. Throughput for OLSR

\begin{tabular}{|c|c|c|c|c|}
\hline $\begin{array}{c}\text { Packet } \\
\text { Type }\end{array}$ & $\begin{array}{c}\text { Mobility } \\
\text { Model }\end{array}$ & $\begin{array}{c}\text { PDR } \\
(\%)\end{array}$ & $\begin{array}{c}\text { Drop } \\
(\%)\end{array}$ & $\begin{array}{c}\text { Average } \\
\text { Throughput } \\
(\mathbf{k b p s})\end{array}$ \\
\hline \multirow{3}{*}{$\begin{array}{c}\text { TCP } \\
\text { Vegas }\end{array}$} & FTM & 97.61 & 2.39 & 2525.38 \\
\cline { 2 - 5 } & IDM-IM & 98.34 & 1.66 & 3786.14 \\
\cline { 2 - 5 } & IDM-LC & 98.67 & 1.33 & 4272.41 \\
\cline { 2 - 5 } & IDM & 98.88 & 1.12 & 4990.43 \\
\hline
\end{tabular}

Table 14. NRL, Route Cost and Mean hop for AODV

\begin{tabular}{|c|c|c|c|c|}
\hline $\begin{array}{c}\text { Packet } \\
\text { Type }\end{array}$ & $\begin{array}{c}\text { Mobility } \\
\text { Model }\end{array}$ & NRL & $\begin{array}{c}\text { Route } \\
\text { Cost }\end{array}$ & $\begin{array}{c}\text { Mean } \\
\text { Hop }\end{array}$ \\
\hline \multirow{2}{*}{$\begin{array}{c}\text { TCP } \\
\text { Vegas }\end{array}$} & FTM & 1.130 & 0.010 & 1.0284 \\
\cline { 2 - 5 } & IDM-IM & 0.738 & 0.007 & 1.0200 \\
\cline { 2 - 5 } & IDM-LC & 0.766 & 0.007 & 1.0207 \\
\cline { 2 - 5 } & IDM & 0.857 & 0.008 & 1.0208 \\
\hline
\end{tabular}

Table 15. NRL, Route Cost and Mean hop for AOMDV

\begin{tabular}{|c|c|c|c|c|}
\hline $\begin{array}{c}\text { Packet } \\
\text { Type }\end{array}$ & $\begin{array}{c}\text { Mobility } \\
\text { Model }\end{array}$ & NRL & $\begin{array}{c}\text { Route } \\
\text { Cost }\end{array}$ & $\begin{array}{c}\text { Mean } \\
\text { Hop }\end{array}$ \\
\hline \multirow{3}{*}{$\begin{array}{c}\text { TCP } \\
\text { Vegas }\end{array}$} & FTM & 1.007 & 0.010 & 1.0272 \\
\cline { 2 - 5 } & IDM-IM & 0.499 & 0.006 & 1.0112 \\
\cline { 2 - 5 } & IDM-LC & 0.544 & 0.006 & 1.0121 \\
\cline { 2 - 5 } & IDM & 0.553 & 0.006 & 1.0081 \\
\hline
\end{tabular}

Table 16. NRL, Route Cost and Mean hop for DYMO

\begin{tabular}{|c|c|c|c|c|}
\hline $\begin{array}{c}\text { Packet } \\
\text { Type }\end{array}$ & $\begin{array}{c}\text { Mobility } \\
\text { Model }\end{array}$ & NRL & $\begin{array}{c}\text { Route } \\
\text { Cost }\end{array}$ & $\begin{array}{c}\text { Mean } \\
\text { Hop }\end{array}$ \\
\hline \multirow{2}{*}{$\begin{array}{c}\text { TCP } \\
\text { Vegas }\end{array}$} & FTM & 1.753 & 0.016 & 1 \\
\cline { 2 - 5 } & IDM-IM & 0.466 & 0.004 & 1 \\
\cline { 2 - 5 } & IDM-LC & 0.509 & 0.005 & 1 \\
\cline { 2 - 5 } & IDM & 0.498 & 0.005 & 1 \\
\hline
\end{tabular}

Table 17. NRL, Route Cost and Mean hop for OLSR

\begin{tabular}{|c|c|c|c|c|}
\hline $\begin{array}{c}\text { Packet } \\
\text { Type }\end{array}$ & $\begin{array}{c}\text { Mobility } \\
\text { Model }\end{array}$ & NRL & $\begin{array}{c}\text { Route } \\
\text { Cost }\end{array}$ & $\begin{array}{c}\text { Mean } \\
\text { Hop }\end{array}$ \\
\hline \multirow{2}{*}{$\begin{array}{c}\text { TCP } \\
\text { Vegas }\end{array}$} & FTM & 0.563 & 0.010 & 1 \\
\cline { 2 - 5 } & IDM-IM & 0.231 & 0.004 & 1 \\
\cline { 2 - 5 } & IDM-LC & 0.205 & 0.004 & 1 \\
\cline { 2 - 5 } & IDM & 0.170 & 0.003 & 1 \\
\hline
\end{tabular}

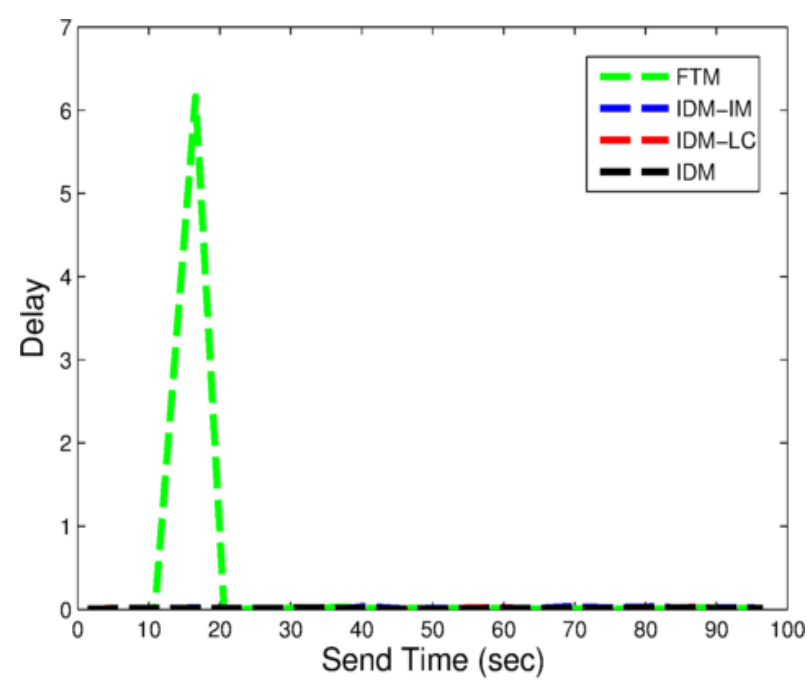

Figure 3: Delay for AODV for $100 \mathrm{sec}$ 


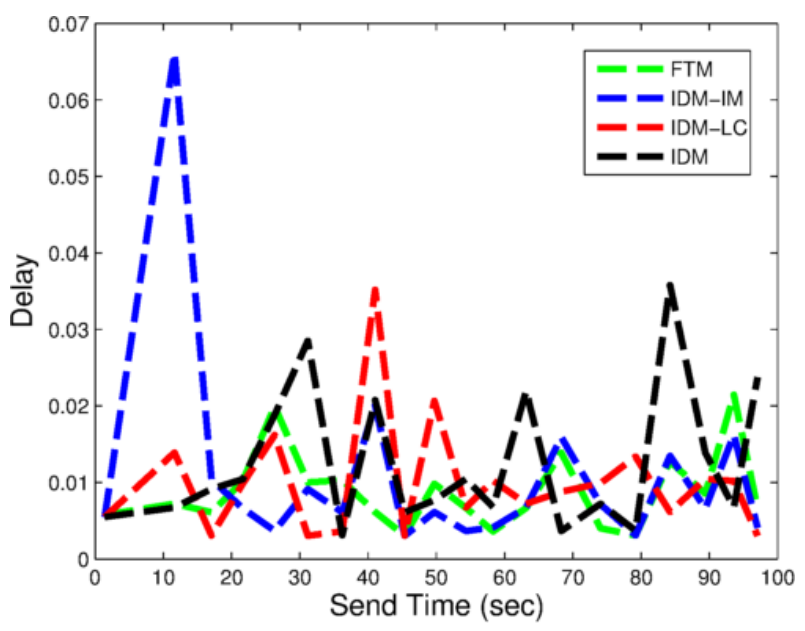

Figure 4: Delay for AOMDV for $100 \mathrm{sec}$

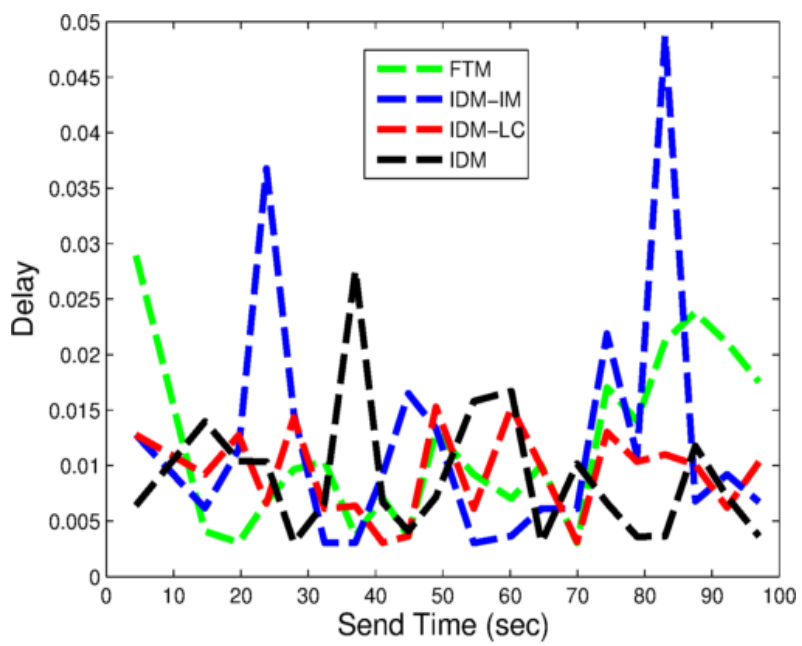

Figure 5: Delay for DYMO for $100 \mathrm{sec}$

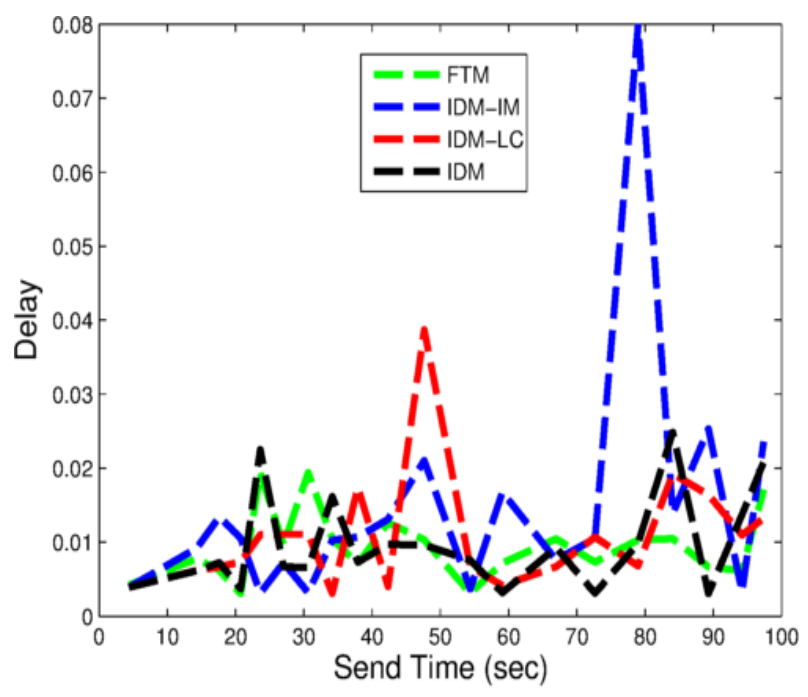

Figure 6: Delay for OLSR for $100 \mathrm{sec}$

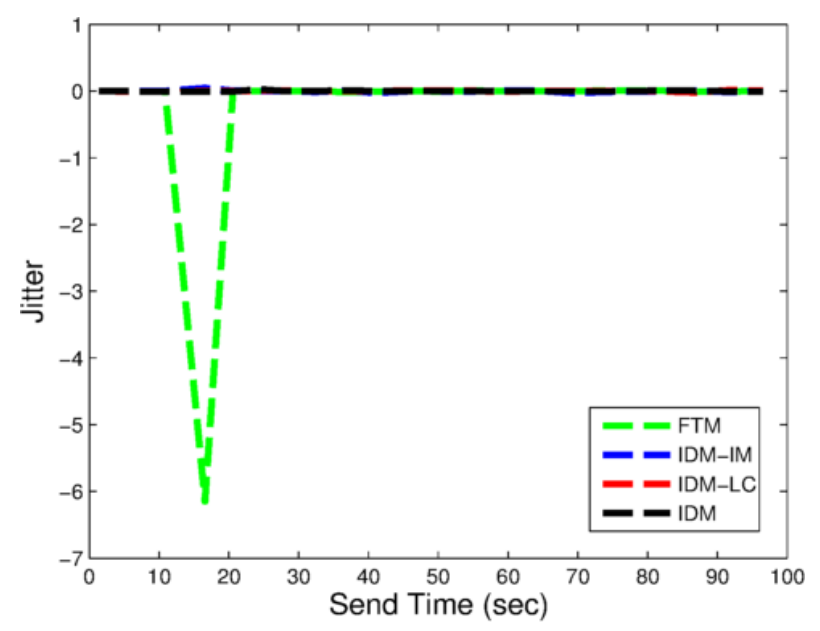

Figure 7: Jitter for AODV for $100 \mathrm{sec}$

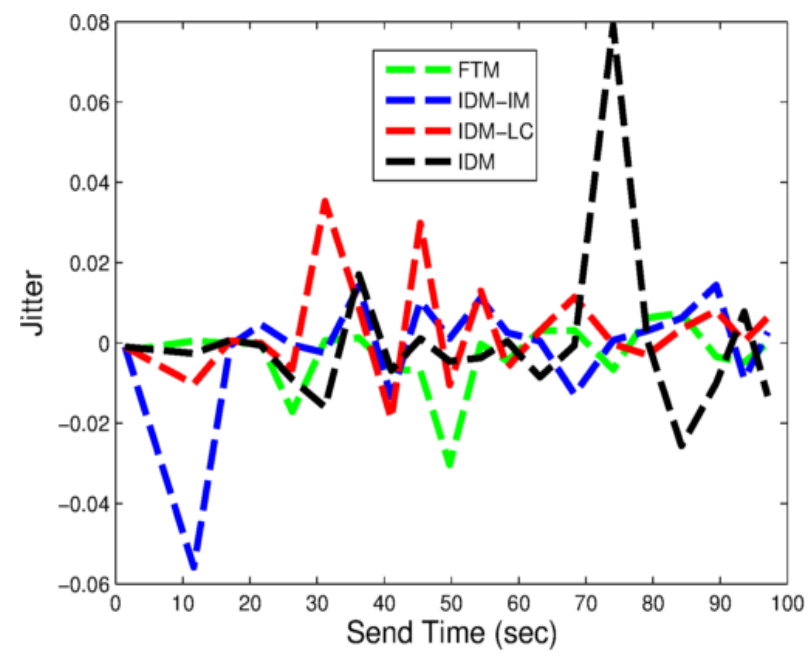

Figure 8: Jitter for AOMDV for $100 \mathrm{sec}$

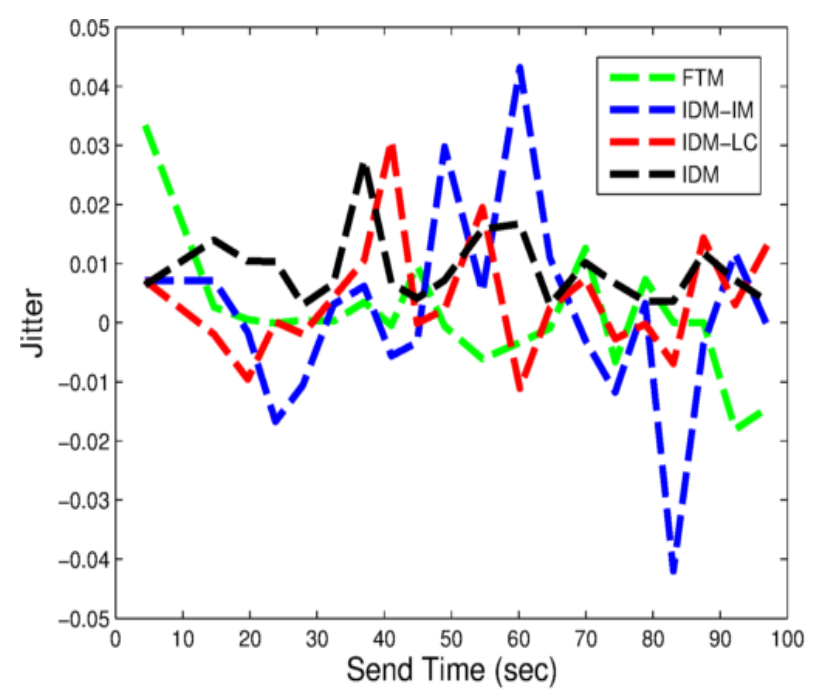

Figure 9: Jitter for DYMO for $100 \mathrm{sec}$ 


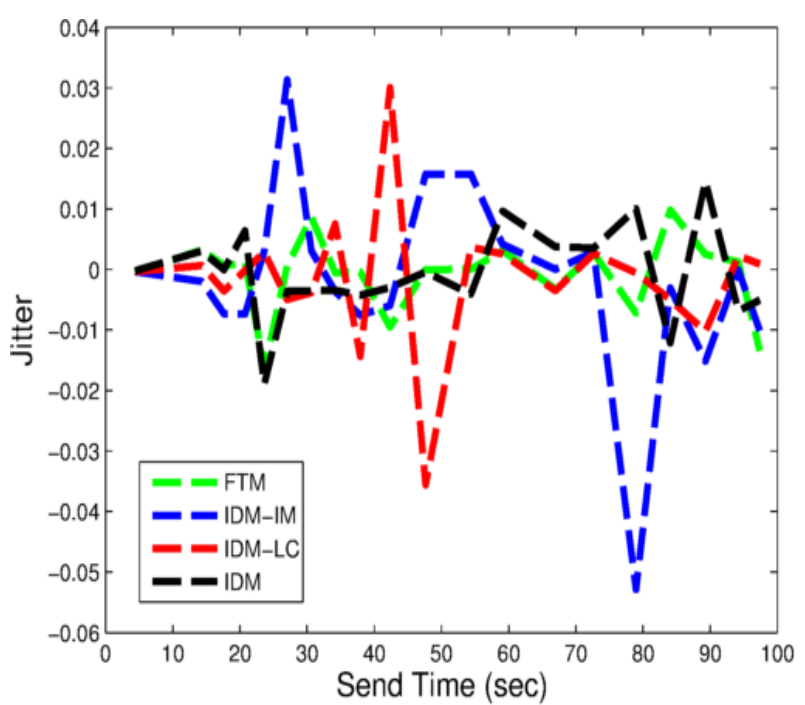

Figure 10: Jitter for OLSR for $100 \mathrm{sec}$

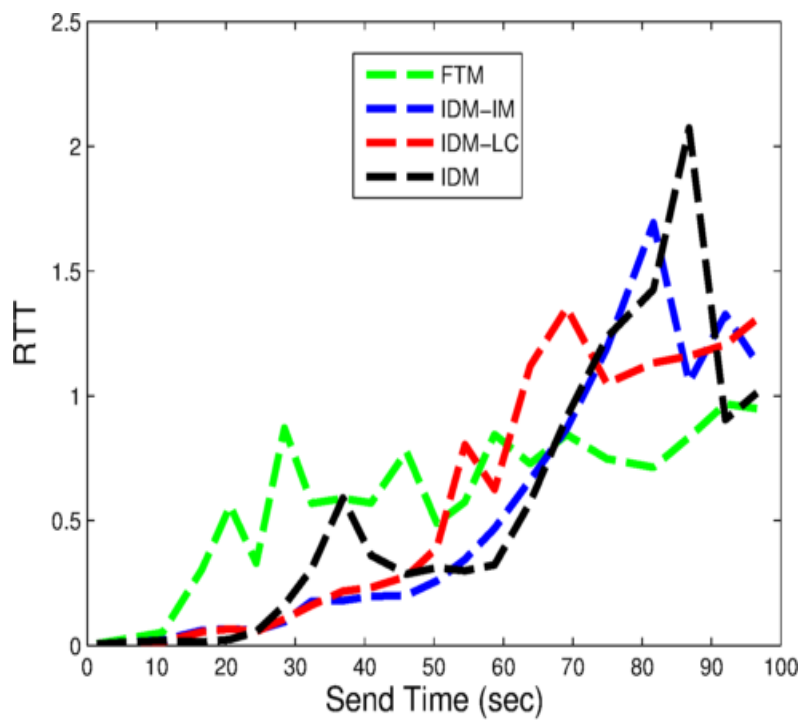

Figure 11: RTT for AODV for $100 \mathrm{sec}$

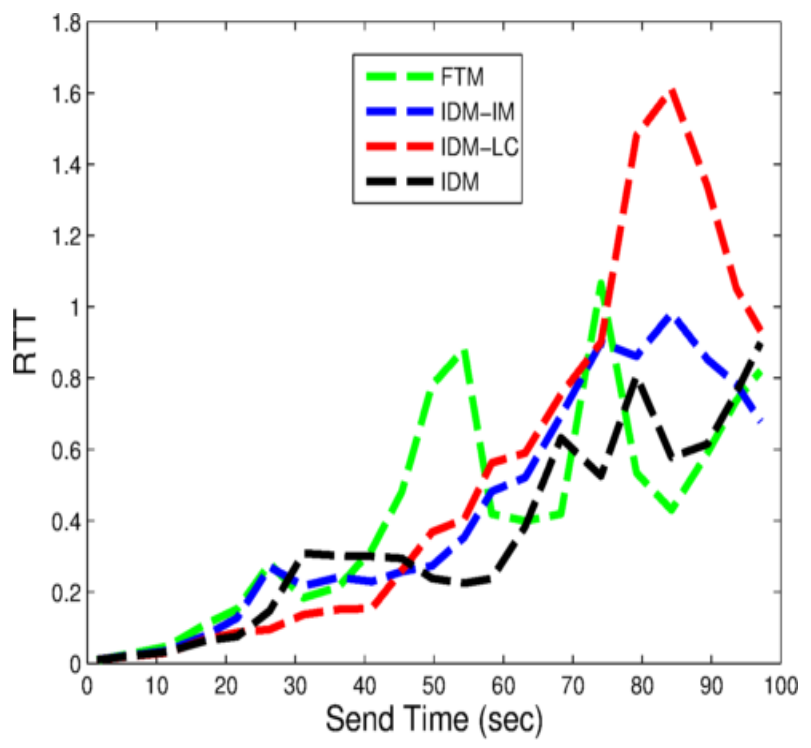

Figure 12: RTT for AOMDV for $100 \mathrm{sec}$

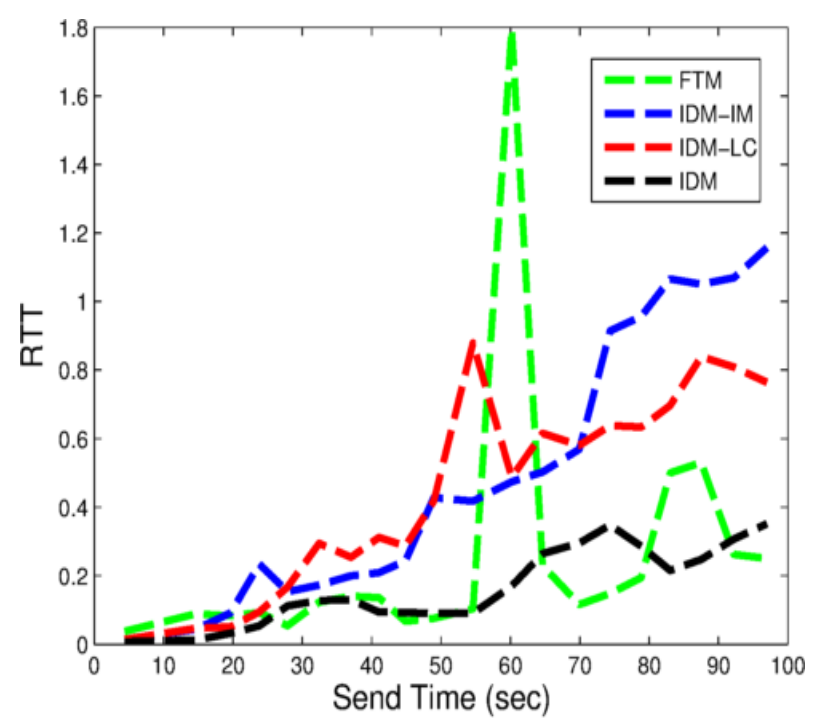

Figure 13: RTT for DYMO for $100 \mathrm{sec}$

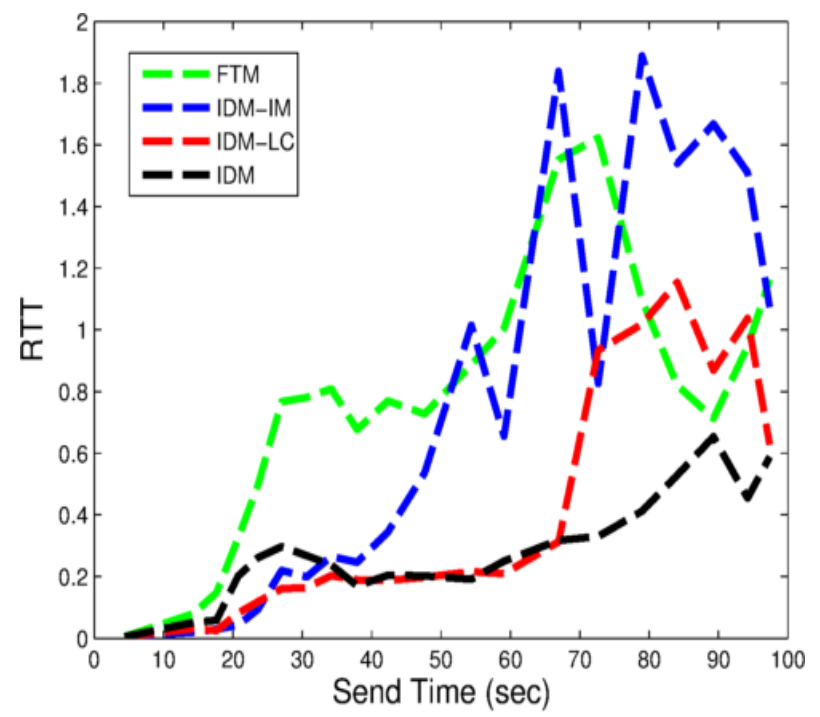

Figure 14: RTT for OLSR for $100 \mathrm{sec}$

\section{CONCLUSIONS}

The simulation results demonstrate that the mobility impact of IDM-IM with respect to Drop rate (1.50\% and $0.93 \%)$, PDR (98.50\% and $99.07 \%$ ), and Average throughput (5171.80 kbps and $5726.06 \mathrm{kbps}$ ) for AODV and AOMDV respectively. Similarly, IDM performs better than three others' mobility models in case of Drop rate $(1.25 \%$ and 1.12 $\%)$, PDR (98.75\% and $98.88 \%)$ and Average throughput (4418.45 kbps and $4990.43 \mathrm{kbps}$ ) in DYMO and OLSR. In AODV, IDM-LC performs better than others in case of mean hop. In AOMDV, IDM outperforms IDM-IM, IDM-LC and FTM with respect to mean hop. In four routing protocols, in case of NRL, and Route Cost where IDM-IM outperforms three others. For delay and jitter calculation of AODV, FTM performs worse than three other. In delay and jitter calculation of AOMDV, FTM and IDM-LC perform comparatively better than IDM and IDM-IM mobility models. IDM-LC and FTM perform slightly better than two others in delay and jitter calculation of DYMO. In delay and jitter calculation of DYMO, FTM and IDM perform marginally better than IDMIM and IDM-LC. In four routing protocol, IDM outperforms than three others mobility models with respect to RTT. The experimental results clearly indicated that the impact of FTM, 
IDM, IDM-IM and IDM-LC mobility model on AODV, AOMDV, DYMO and OLSR routing protocol performances were not up to the mark for each of the parameters of performance metrics/QoS metrics towards the development of realistic vehicular applications.

\section{REFERENCES}

[1] W. Alasmary and W. Zhuang, "Mobility impact in IEEE 802.11 p infrastructureless vehicular networks," Journal in Ad Hoc Network, Mar. 2010.

[2] D. Jiang and L. Delgrossi, "IEEE 802.11p: Towards an international standard for wireless access in vehicular environments," pp. 2036-2040, 2008.

[3] T. Kaur and A. Verma, "Simulation and analysis of AODV routing protocol in VANETs," Int. Journal of Soft Computing and Engineering (IJSCE), Vol. 2(3), pp. 293-301, Jul. 2012.

[4] V. Godbole, "Intelligent driver mobility model \& traffic pattern generation based optimization of reactive protocols for vehicular ad-hoc networks," International Journal of Information and Network Security (IJINS), Vol. 2(3), pp. 207-214, Jun. 2013.

[5] R. Boopathi and R. Priya, "Performance evaluation of AODV and OLSR in VANET under realistic mobility pattern," Int. Journal of Electronics and Communication Engineering \& Technology, Vol. 4(2), pp. 58-71, 2013.

[6] S. Xu, P. Guo, B. Xu and H. Zhou, "QoS evaluation of VANET routing protocols," Journal of Networks, Vol. 8(1), pp. 132-139, Jan. 2013.

[7] H. Wang, G. Tan and J. Yang, "An improved VANET intelligent forward decision-making routing algorithm," Journal of Networks, Vol. 7(10), pp. 1546-1553, Oct. 2012.

[8] M. Jerbi, S. Senouci and Y. Ghamri-Doudane, "Towards efficient geographic routing in urban vehicular networks," Trans. on Vehicular Technology, Vol. 58(9), pp. 5048-5059, Nov. 2009.

[9] K. Lan and C. Chou, "Realistic mobility models for vehicular ad hoc network (VANET) simulations," $8^{\text {th }}$ Int.
Conf. on ITS Telecommunications, pp. 362-366, Oct. 2008.

[10] C. Han, M. Dianati, R. Tafazolli, R. Kernchen and X. Shen, "Analytical study of the IEEE 802.11p MAC sublayer in vehicular networks," Trans. on Intelligent Transportation Systems, Vol. 13(2), 873-886, Jun. 2012.

[11] V. Cabrera, F. Ros and P. Ruiz, "Simulation-based study of common issues in VANET routing protocols," $69^{\text {th }}$ Vehicular Technology Conference, 2009.

[12] S. Gwalani, E. Belding-Royer and C. Perkins, "AODVPA: AODV with path accumulation," Int. Conf. on Communications, Vol. 1 pp. 527-531, May 2003.

[13] X. Du, Y. Wang, J. Ge and Y. Wang, "A method for security enhancements in AODV protocol," $17^{\text {th }}$ Int. Conf. Proc. on Advanced Information Networking and Applications (ICPAINA), pp. 237-240, Mar. 2003.

[14] A. Chintawar, M. Chatterjee and A. Vidhate, "Performance analysis of ad-hoc on-demand multipath distance vector routing protocol with accessibility and link breakage prediction," $2^{\text {nd }}$ Int. Conf. and Workshop on Emerging Trends in Technology (ICWET), 2011.

[15] S. Mallapur and S. Terdal, "Enhanced ad-hoc on-demand multipath distance vector routing protocol (EAOMDV)," International Journal of Computer Science and Information Security (IJCSIS), Vol. 7(3), Mar. 2010.

[16] S. Kumar, S. Khimsara, K. Kambhatla, K. Girivanesh, J. Matyjas, and M. Medley, "Robust on-demand multipath routing with dynamic path upgrade for delay sensitive data over ad hoc networks," Journal of Computer Networks and Communications, 2013.

[17] C. Perkins, S. Ratliff and J. Dowdell, "Dynamic manet on-demand routing," IETF Internet Draft, draft-ietfmanet-dymo-26.pdf, Feb. 25, 2013.

[18] T. Clausen and P. Jacquet, "Optimized link state routing protocol for ad-hoc networks," Network Working Group, Internet Draft, rfc3626.txt, Oct. 2003.

[19] M. Fiore, J. Härri, F. Fethi, and C. Bonnet, "Vehicular mobility simulation for VANETs," $40^{\text {th }}$ IEEE Annual Simulation Symposium (ANSS), Mar. 2007. 